\title{
Relationships between early flavor exposure, and food acceptability and neophobia
}

Sophie Nicklaus

Center for Taste and Feeding Behaviour (CSGA), CNRS, INRA, Université de Bourgogne Franche-Comté, Dijon, France

\subsection{Introduction}

Eating behavior is a complex activity which is critical for development and survival. It is essentially learned, in particular during early years (Nicklaus, 2015; Nicklaus and Remy, 2013; Schwartz et al., 2011b). It can be broken down into several components: when, how, what, and how much to eat (Butte et al., 2004; Schwartz et al., 2011b). We will mainly focus here on the influence of early flavor exposure on the development of "what" to eat, or in other words, food preferences and choices, including food neophobia. It is relevant to focus on early flavor exposure because food habits are formed early during childhood, under the effect of experience, and are likely to track over childhood, until the beginning of adulthood (Nicklaus et al., 2004, 2005a).

The present chapter is organized in three main sections. In the first section, an overview of what is known about of early flavor exposure, distinguishing between taste and flavor (aromatic) exposure, is provided. In the second section, we will describe what has been researched regarding the influence of early flavor exposure on the development of food preference, looking at prenatal exposure, exposure received in the context of milk feeding, and exposure received in the context of complementary feeding. The third section describes what has been shown regarding the relationships between early flavor exposure and food neophobia. For further information regarding the mechanisms underlying the learning process described here, the reader may refer to chapter: Learning of Human Flavor Preferences.

\subsection{Early flavor exposure}

Here, we briefly describe the types of flavor exposure received by fetuses, infants, and toddlers. Further information about flavor exposure in biological fluids may be found in chapter: How Amniotic Fluid Shapes Early Odor-Guided Responses to Colostrum and Milk (and More). Whereas it is now more and more widely acknowledged that early exposure to environmental stimulus may alter metabolic functions on the short 
and on the long run (Bateson et al., 2004), exposure to flavor has only been recently looked at, compared to, for instance, nutritional (Gillman and Ludwig, 2013; Singhal et al., 2001) or other environmental exposure (Prescott, 2010).

Food preferences are learned from experience, and experiences likely to shape food preference start very early, in utero. Hence, we will describe here the early flavor exposure starting in utero. Whenever possible, we describe separately exposure to taste compounds from exposure to aromatic compounds because their sensing pathways are different.

\subsubsection{Flavor exposure in utero}

During fetal life, the fetus is exposed to a fluid with an evolving composition according to the metabolic and nutritional status of the mother. In particular, the amniotic fluid flavor properties are likely to be modified by the flavors of the foods consumed by the mother during pregnancy (Schaal, 1988): for instance, the flavor of garlic (Hepper, 1995), cumin seeds (Schaal and Orgeur, 1992), anise (Schaal et al., 2000), or carrot (Mennella et al., 2001) are likely to be transferred to the amniotic fluid. The flavors of undesirable compounds such as alcohol and nicotine are also likely to be present in the amniotic fluid, although in this area, the evidence is indirect in humans, or based on animal studies (Mantella et al., 2013).

The amniotic fluid also contains compounds that are likely to impart taste: mineral salts, including sodium which contributes to the salty taste, urea which has a bitter taste, glucose which is sweet, etc. (Schwartz et al., 2009). It is certainly possible that the intensity of this exposure may vary according to the maternal serum concentration, and to maternal condition, but very few studies have systematically looked at characterizing the taste and flavor properties of amniotic fluid. Notably, glucose concentration in amniotic fluid appears to be higher in infants carried by mothers with gestational diabetes mellitus, than in those carried by healthy mothers (Tisi et al., 2011).

Chemosensory exposure during fetal life becomes especially important when the fetus starts swallowing, that is, after the sixth month of gestation (Schaal, 1988). The circulation of the amniotic fluid in relation to swallowing makes the renewing of the molecules in contact with the olfactory epithelium and taste buds possible, a fact that enables the emergence of a stimulation.

\subsubsection{Flavor exposure in lacto}

After birth, infants are exposed during several months to a single food, milk, which may come from the breast or be commercially prepared (formula). The breast may be flavored by conspecific odorants (Schaal et al., 2008). Breast milk contains a variety of flavor compounds: acids, alcohols, aldehydes, alkenes, aromatic compounds, esters, heterocyclic compounds, ketones, lactones, terpenes, sulfides (Bingham et al., 2003b; Buettner, 2007; Hausner, 2009; Shimoda et al., 2000). Moreover, in much the same way as amniotic fluid is flavored by the foods consumed by the mother during pregnancy, breast milk may be flavored by the foods consumed by the 
mother during lactation. Thus, the flavors of breast milk are likely to vary from one feeding episode to another (Mennella, 1995). Moreover, the flavors of breast milk are also likely to vary within one feeding episode, as fat content of milk is increasing during feeding (Emmett and Rogers, 1997; Jensen, 1995), which may modify the saturation point of the flavor compounds. Several dietary compounds of the mother have been identified in breast milk: vanilla (Mennella and Beauchamp, 1996b), carrot (Mennella et al., 2001), garlic (Mennella and Beauchamp, 1991a, 1993), alcohol (Mennella, 2001; Mennella and Beauchamp, 1991b), D-carvone (Hausner et al., 2010), nicotine and caffeine (Geraghty et al., 2015). However, some studies showed that some compounds from herbal tea are not transferred in breast milk (Denzer et al., 2015). Analysis of retrieval of different flavors (3-methylacetate, L-menthol, D-carvone, trans-anethole) in breast milk revealed several facts (Hausner et al., 2009): one compound was not retrieved (3-methylacetate), probably as it was metabolized; for the other compounds, the time of maximal concentration in breast milk peaked at $2 \mathrm{~h}$ postingestion (D-carvone, trans-anethole), or plateaued from 2-8 $\mathrm{h}$ postingestion; the concentration in milk was highly variable from one woman to the other, revealing different aptitudes to metabolize these compounds, and suggesting a high variability in exposure from one infant to the other.

The flavors of formula milks may be viewed as more constant; however, they are also likely to differ according to the formula types (Schwartz et al., 2010). Concerning odorants, a comparison of the chromatograms of mother's milk and infant formula revealed that, on average, mother's milk contained twice as many volatile compounds than formula (Hausner et al., 2008). Moreover, from a qualitative point of view, both types of milk were rich in lipid-derived volatile compounds; but formulas contained more volatiles related to thermal treatment; and breast milk presented a higher variety of terpenes. Concerning tastes, different formulas may present different sensory profiles (Mennella et al., 2009; Schwartz et al., 2010): antiallergic formulas are prepared with hydrolyzed proteins which have a bitter and sour taste; antidiarrheal formulas may contain more salt, and thus be saltier than regular formula; fermented formulas may be sourer than regular ones.

\subsubsection{Flavor exposure in complementary foods}

After the initiation of complementary feeding, infants become exposed to a wider variety of foods from different groups (cereals, vegetables, fruits, meat, fish, cheese, cakes, convenience foods, etc.), which increase the diversity of flavor, taste, and texture exposure they receive (Nicklaus, 2011; Nicklaus et al., 2015). Describing the complexity of the flavor exposure infants receive through complementary foods is a challenge because each individual food is composed of several odor compounds; thus, it appears easier to describe the perceived odor of the foods (Wagner et al., 2014). Describing the tastes of the foods infants receive is a first step that some teams initiated, based on sensory profiles of foods undertaken by adult panels (Martin et al., 2014; Schwartz et al., 2010; Viskaal-van Dongen et al., 2012). It should be more systematically conducted, in order to enable a better understanding of taste exposure over the first year (Schwartz et al., 2010, 2011a). 


\subsection{Influence of early flavor exposure on the development of food preferences}

\subsubsection{Influence of in utero flavor exposure}

The possibility that uterine flavor exposure may impact the future development of food preference and, by extension, eating behavior implies that the fetus is able to detect the flavors, and to memorize them. Several bodies of evidence confirm that the olfactory and taste sensing systems are functional before birth, around the end of the second trimester of gestation for the taste system (Ganchrow and Mennella, 2003), and by the seventh month for the olfactory system (Marlier, 2009; Marlier et al., 2001; Schaal, 1988). For instance, preterm born infants are able to differentiate the odor of vanilla from that of butyric acid, and exhibit more negative facial expressions when smelling the odor of butyric acid (Marlier et al., 2001). Moreover, it was shown in preterm newborns that the presentation of a vanilla odor in the incubator is likely to modify the premature newborn's physiological state, as attested by the reduction of sleep apnea in presence of vanilla (Marlier et al., 2005).

The fine olfactory capacities of newborns are also attested by studies showing their preference for the odor of amniotic fluid, compared to the odor associated with postnatal foods (Marlier et al., 1998). This reveals that, even in the young organism, familiarity with a flavor is an important component of the preference/acceptance of this flavor.

The effect of uterine exposure to the flavors of dietary compounds ingested by the mother during pregnancy was studied at different developmental stages, and through different approaches. During the first hours or days after birth, it was shown that newborns exhibit a higher preference for an odor experienced in utero, after the consumption by their mother of foods flavored with this odor, than newborns whose mother had not consumed such an odor during pregnancy; this was observed after the consumption of garlic (Hepper, 1995) and of anise-flavored foods (Schaal et al., 2000). When infants are presented with some of their first complementary foods, around the age of 6 months, it was shown that those whose mother had consumed carrot juice for 3 weeks at the end of pregnancy exhibited less negative facial reactions when tasting a carrot-juice flavored cereal than a plain cereal, compared to those whose mother had not consumed carrot juice (Mennella et al., 2001). On a longer run, it was also shown that school-aged children (8-9 years) prenatally exposed to garlic ate more garlic-flavored potato gratin than plain potato gratin than their peers who had not been prenatally exposed to garlic (Hepper et al., 2013). These studies show that the exposure to a specific flavor compound in utero is associated to behavioral modifications in postnatal life that have been assessed for compounds/foods bearing a similar flavor. More generally, one may wonder whether "generalized" dietary exposure during this period is likely to affect food acceptance later in life. An analysis in an Australian cohort that compared the effect of maternal dietary exposure to fruit and vegetable during pregnancy, and in early childhood, on children's acceptance of fruit and vegetables revealed that the effect of maternal diet during early childhood was prominent (Ashman et al., 2014). The analysis of data from a French cohort, focusing 
on maternal vegetable dietary variety during pregnancy, also concluded to an absence of effect of maternal variety of vegetable during pregnancy on children's acceptance of vegetables at 2 years (Nicklaus et al., 2014).

Evaluation of the effect of uterine exposure to tastants is generally indirect. It was reported that if mothers had more frequent/stronger vomiting episodes during pregnancy, which is likely to be associated with mineral and sodium loss, the progeny is more likely to have a different behavior toward sodium. For instance, 16-week-old infants exhibit less negative facial expressions when tasting salty water, and consume more of it (Crystal and Berstein, 1998), and adolescents have a higher salt use and consume more salty foods (Crystal and Berstein, 1995). In a similar fashion, early events leading to sodium loss, such as vomiting episodes or diarrhea, may lead to an increased preference for the salty taste (Leshem, 1998). As noted previously, such effects are relatively persistent over childhood, as they were observed when children are aged 8-15 years (Shirazki et al., 2007); and in teenagers aged 16-20 years (Crystal and Berstein, 1995; Málaga et al., 2005). Animal studies further show that maternal consumption of Acesulfame-K (a nonnutritive sweetener) during pregnancy is associated with an increased preference for the sweet taste in the progeny (Zhang et al., 2011).

Animal studies also bring interesting evidence regarding the effect of alcohol and nicotine consumption during pregnancy, which are difficult to assay in humans for ethical reasons. In humans, prenatal alcohol exposure is associated with a decreased ability to identify odors, in school-aged children (Bower et al., 2013). Experimental evidence suggests that exposure to alcohol during late uterine life is associated with the development of a preference for alcohol (Abate et al., 2008), in complement with other unwanted consequences of prenatal alcohol exposure. In a similar way, fetal nicotine exposure may increase preference for nicotine odor in the offspring, but only at early stages during adolescence, not in adults (Mantella et al., 2013).

The mechanisms underlying these changes can only be explored in animals. Prenatal flavor exposure may affect a variety of feeding behaviors and physiological processes (Oostindjer et al., 2009, 2010, 2011), and affect the development of the olfactory bulb (Todrank et al., 2011). As suggested by studies of perinatal odor exposure, it may also affect the development of the olfactory epithelium (Cadiou et al., 2014).

That prenatal exposure to a flavor is associated with postnatal development of a preference for this flavor may be seen as an adaptive mechanism that prepares the developing organism to postnatal life, in an environment where the flavor cues with biological significance are likely to resemble those present during the developmental course in utero. When the flavor cues are associated with unhealthy substances, the effects of this learning are not adaptive.

\subsubsection{Influence of flavor exposure during the milk feeding period}

Dietary flavor exposure during the milk feeding period may originate from breast, breast milk, formula, or other beverages.

The human breast emits odorants (Schaal et al., 2006, 2008) that help guiding the infant toward the nipple, and facilitate the transition toward oral feeding after birth 
(Doucet et al., 2009, 2012; Porter and Winberg, 1999). Even in preterm infants, breast milk odor triggers nonnutritive sucking (Bingham et al., 2003a, 2007) and it attracts infants, as demonstrated by cephalic orientation in term-born infants (Marlier and Schaal, 2005; Marlier et al., 1997). The breast may also carry flavors from pomades, perfumes, and other cosmetic products. The nursing situation represents a highly positively reinforcing event. It was observed that an odor experienced by the infant at the breast becomes more liked by infants than a nonexperienced-odor, and equally liked as milk (Delaunay-El Allam et al., 2006). This increased preference for the breastassociated odor was stable when infants were aged 7 and 21 months (Delaunay-El Allam et al., 2010).

Learning of specific flavor compounds occurs during breastfeeding. Maternal consumption of specifically flavored foods during nursing is associated to higher acceptance of foods bearing similar flavors, after the onset of complementary feeding, compared to the absence of consumption: this was observed when carrot was consumed (Mennella et al., 2001), or a caraway-flavored food (Hausner et al., 2010). However, a study with exposure to carrot during nursing showed a lower acceptance of carrot-prepared cereals than of plain cereals, just after breast-milk consumption (Mennella and Beauchamp, 1999). More generally, experiences in the breastfeeding context are likely to influence the infant's eating behavior. Compared to formula-fed infants, breastfed infants display a higher acceptance of a new food, when acceptance is evaluated during the first days of the complementary feeding period (Jagnow et al., 2000; Maier et al., 2008; Sullivan and Birch, 1994), or within 1 month after the onset of complementary feeding (Hausner et al., 2010). However, this difference is not observed anymore when acceptance of new foods is averaged over a 2-month period (Lange et al., 2013). Moreover, after 10 days of exposure to a flavored food, breastfed and bottle fed infants do not differ in their acceptance of this food, compared to an unflavored version (Hausner et al., 2010).

Beyond the exposure to specific flavor compounds, the positive impact of breastfeeding on further food acceptance may be mediated by the variety of flavor exposure in the milk context (Hausner et al., 2010; Mennella et al., 2001). This impact may be limited to the very beginning of complementary feeding (Hausner et al., 2010). Flavor learning is also likely to happen in the context of formula feeding. A study evaluated the impact of experience with formula, which was flavored with vanilla during a certain period of time, or with breast milk (Haller et al., 1999). Adults had to express their preference for a plain ketchup or a ketchup flavored with vanilla at a "barely detectable" level. Two-thirds of the formula fed participants preferred the vanilla-flavored ketchup, while two thirds of the breast fed participants preferred the plain ketchup. This confirms the flavor learning effect in the milk feeding context, and also reveals that such an effect is likely to have long lasting consequence.

The taste experience in the milk feeding context may also modify further food preferences. The longer the breastfeeding duration, the higher the acceptance of a umami-tasting solution at the age of 6 months (Schwartz et al., 2013), which may be interpreted in relation with the high glutamate content of breast milk, compared to formula (Agostoni et al., 2000). Exclusive breastfeeding was also shown to be associated with a lower acceptance of salty cereals, compared to plain cereals in 4- to 
6-month-old infants, which may be related to the lower sodium content of breast milk, compared to formula (Harris et al., 1990). Exposure to hydrolyzed-protein formula, which has stronger bitter, sour, and umami tastes than regular formula, is associated to a higher preference for sour, bitter, or umami cereal at the beginning of complementary feeding (Mennella et al., 2009), and to different taste preference patterns for fruit juices with modified tastes, up to the age of 5 years (Liem and Mennella, 2002; Mennella and Beauchamp, 2002). Does exposure to hydrolyzed-protein formula impact acceptance of bitter foods? Infants aged 5-11 months previously exposed to hydrolyzed-protein formula reject more a broccoli/cauliflower puree than infants fed with a regular formula (Mennella et al., 2006), but at 4-5 years mothers report that exposed children liked it better than those who consumed regular formula (Mennella and Beauchamp, 2002). Furthermore, it was demonstrated that hydrolyzed-protein formula may be preferentially accepted only during a certain time window. It is easily accepted at the age of 2 months, but not at the age of 7 months (Mennella and Beauchamp, 1996a), except if at this age the infant had received previous exposure to such a formula type (Mennella et al., 2004). Moreover, the earlier the exposure to hydrolyzed-protein formula, and the longer the exposure, the higher its acceptance (Mennella et al., 2011). In other respect, it was observed that infants exposed to sugar water during the milk feeding period had a higher preference for the sweet taste in water at 6 and 24 months (Beauchamp and Moran, 1982, 1984), but this effect was not generalized to other sweet beverages.

Epidemiological studies complement the reported experimental observations related to the effect of the type of milk feeding by revealing the association between breastfeeding practices and dietary habits at a later age. Breastfeeding duration is positively associated to food variety later: it is associated to variety of free food choices by 2- to 3-year-old children (Nicklaus et al., 2005b), to healthy eating habits at 2 years (Abraham et al., 2012), to food variety at 2 years (Scott et al., 2012), to fruit consumption at 6-8 years (Skinner et al., 2002b), and to a healthy eating pattern (consumption of meat, fruits, and vegetables) at 2-8 years (Grieger et al., 2011). A longer breastfeeding duration was consistently related to higher fruit and vegetable intake in 2- to 4-year-old children, when taking into account data from four different European cohorts (de Lauzon-Guillain et al., 2013). Exclusive breastfeeding for at least 3 months is associated with a higher consumption of vegetables at 4 years (Burnier et al., 2011). These effects may be partly mediated by the exposure to a more varied flavor profile in the context of breastfeeding, compared to formula feeding; however, it does not preclude the possibility for other factors to be involved in this phenomenon: for instance, breastfeeding could be associated to a better development of oral abilities that may help the transition to solid foods (Nicklaus et al., 2015), and it may be associated to different maternal attitudes regarding child feeding (Taveras et al., 2004, 2006).

\subsubsection{Flavor exposure at the onset of complementary feeding}

Introduction to complementary foods is a process which corresponds to the transition between a single food, milk, toward a diversity of family foods. At the 
age when complementary feeding is recommended to be conducted, around 6 months (WHO, 2003), the infant displays limited physiological capacities (ie, intestinal maturity, renal functions, and oral function development), and therefore family foods need to be adapted. They are adapted in terms of nutritional content (The Commission of the European Communities, 2006). They are also often adapted in terms of texture, and are initially offered in the form of purees or soup because of the limited oral skills of the infant (Nicklaus et al., 2015). Despite its importance, the role of texture will not be discussed further here.

The sensory properties of complementary foods may partly determine their acceptance, as will be described here. Moreover, several factors related to flavor exposure are now known to be involved in the acceptance of foods at complementary feeding, in particular factors likely to determine the flavor exposure infants receive, such as repeated exposure, and variety of foods offered.

\subsubsection{Flavor acceptance at the onset of complementary feeding}

The analysis of the acceptance of all new foods offered to a sample of French infants, at the beginning of complementary feeding, showed that most foods $(90 \%)$ were accepted, with a slightly lower acceptance of vegetables and fruits (Lange et al., 2013). A more detailed analysis of the tastes of complementary foods offered between 5 and 7 months showed that reactions to new vegetables were more positive if the vegetable was salted, or contained a salty ingredient (Schwartz et al., 2011a). That salt may trigger a higher food intake was also observed in toddlers (Bouhlal et al., 2011). Dietary exposure to sodium in complementary foods was shown to be associated with a higher acceptance of salty taste in preschoolers (Stein et al., 2012).

The contribution of flavor as a whole to the initial acceptance of vegetables can be interpreted by comparing the effect of exposure to a variety of vegetables on the acceptance of carrot (Gerrish and Mennella, 2001) or of green beans (Mennella et al., 2008). Acceptance of green bean appears more difficult to promote than that of carrot, no doubt in part due to the difference in tastes of the two vegetables, with one being sweeter than the other. Moreover, a study showed that the acceptance of green beans is easier to enhance than the acceptance of artichoke (Barends et al., 2013).

Individual differences in reactivity to tastes may explain differential acceptance of new foods at the beginning of complementary feeding (Schwartz et al., 2011a): at the age of 6 months, infants who accepted more easily the sour, umami, and sweet tastes in water solutions also displayed more positive reactions toward sour-, umami-, and sweet-tasting complementary foods, respectively. In a similar fashion, individual differences in reactivity to food odors were shown to explain differences in reactions toward new foods (Wagner et al., 2014): at the age of 12 months, the more toddlers liked the odor of trimethylamine (fish odor), the more their parents reported they liked fish; and the more they liked the odor of dimethyl disulfide (sulfurous odor of some cheeses and of some vegetables), the more their parents reported they liked cheese with a sulfurous flavor note (eg, camembert, Munster, Epoisses), and the more they tend to like vegetables with a sulfurous flavor note (eg, broccoli, cabbage, cauliflower, Brussels sprouts, leek). 


\subsubsection{Role of repeated exposures}

The repetition of exposures to a food is one of the primary determinants of its acceptance beyond the initial reaction the food may trigger. Several studies have shown that a food is consumed more, and is judged by an adult (generally the mother) as more liked by the infant after several offers. The first study related to the effect of exposures in infants at the beginning of complementary feeding clearly demonstrated an increase in acceptance of a new green vegetable after 10 exposures (Sullivan and Birch, 1994). A further study also showed a similar exposure effect: after eight exposures to a new fruit or vegetable, intake increased (Birch et al., 1998). The effect of repeated exposures was potent enough to increase the acceptance of foods which had been previously identified by the mother as being refused by her infant at the beginning of the complementary feeding process, which were most often green vegetables, but also pumpkin (Maier et al., 2007).

Repeated exposure to foods with an added flavor may help increase their acceptance even in a plain version, if the flavor is liked: this is described as flavor-flavor learning. In infants at the start of the complementary feeding period, repeated exposures were shown to be as effective as associating a new vegetable with a liked flavor (the sweet taste) to increase its intake (Forestell and Mennella, 2007; Remy et al., 2013); whereas associating it with a higher energy content (by adding oil) did not increase its intake, probably through learned satiation (Remy et al., 2013). In older children (1-3 years), the same effects were observed; but the effect of learning was attenuated, compared to that in infants (Caton et al., 2014). In toddlers aged 2-3 years, repeated exposure to a new vegetable, salsify, with a pinch of salt $(0.2 \% \mathrm{w} / \mathrm{w} \mathrm{NaCl})$, led to a higher increase in salsify intake than flavor-flavor learning with a higher salt content $(0.5 \% \mathrm{w} / \mathrm{w} \mathrm{NaCl})$ or with nutmeg flavor (Bouhlal et al., 2014). In toddlers aged 1.5-4 years, a significant increase in intake was observed after seven exposures to vegetable crisps offered with a liked dip (flavor-flavor learning) or with a neutral dip (simple repeated strategy) (de Wild et al., 2014). Description of the effects of repeated exposure and of flavor-flavor learning beyond the complementary feeding period can be found elsewhere (Issanchou and Nicklaus, 2015).

\subsubsection{Role of the variety of foods offered}

As described previously, repeated offerings of a given food may enhance its acceptance. Moreover, repeated offerings of a variety of foods may also promote the acceptance of an unknown food. Infants aged $\sim 6$ months were shown to better accept carrot, a new food, either if they had been repeatedly exposed to carrot (repeated exposure effect) or to a variety of foods differing from 1 day to the next, but not if they had been repeatedly exposed to potato (Gerrish and Mennella, 2001). Moreover, infants in the variety group better accepted chicken than children in the two other groups. Further studies showed that this "exposure to food variety" effect might enhance the acceptance of a less liked food than carrot, such as green bean, only if the exposure to variety is higher than the variety necessary to increase acceptance of carrot (Mennella et al., 2008). Green bean acceptance increased only if in the variety condition, where pairs of different foods were presented over several days, not if different foods were 
presented over several days (Mennella et al., 2008). This suggests that exposure to a variety of flavors or foods might be interpreted at the day level or at the meal level. A practical consequence of this observation is that introducing more than one food per eating occasion (ie, more flavor variety) might be a way to enhance exposure to flavor variety, and therefore acceptance of new foods.

The role of timing of exposure to flavor variety was explored. A study revealed that offering three different foods 3 times, by alternating foods from 1 day to the next, resulted in a higher acceptance of new foods than offering each of the three different foods for a period of 3 days (Maier et al., 2008). This effect was observed for several new foods (zucchini-tomato, peas, meat, and fish). Furthermore, it was suggested that the efficiency of the exposure to variety effect may depend on the infant age at the beginning of complementary feeding (Coulthard et al., 2014). This study showed that among children introduced to complementary foods after 5.5 months, the acceptance of a new food, pea, was higher in infants previously exposed to a variety of foods (and thus of flavors) than in infants previously exposed to a single food (but there was no difference between exposure groups when infants were weaned before 5.5 months). Altogether, these findings suggest that exposure to "flavor" variety is a robust mechanism favoring the acceptance of new foods.

A randomized controlled trial conducted in the United Kingdom, Greece, and Portugal specifically investigated whether exposure to a variety of vegetables early in the complementary feeding process would prevent the observed decline in liking, and intake of vegetables at a later age (Fildes et al., 2015). Parents of 4- to 6-month-old infants were randomized to receive shortly before the start of complementary feeding either (1) guidance on introducing a variety of culturally appropriate vegetables as first complementary foods, or (2) usual care. Infants in the intervention groups showed increased consumption and liking of an unfamiliar vegetable in the short term, but only in countries where single vegetables are not already amongst the common first foods offered to infants (United Kingdom and Greece). Beneficial effects of the intervention were not maintained at the 6- or 9-month follow-up, although results from the Greek sample suggest that there may be a positive effect of the intervention on vegetable variety, and general vegetable acceptance.

\subsection{Relationships between flavor exposure, flavor preferences and neophobia}

As children grow older, they may develop a neophobic phase when they start to refuse foods, even if they previously enjoyed them (Dovey et al., 2008; Nicklaus, 2009). The food neophobia and pickiness phase is associated with consequences on children's food choice. The variety of free food choices decreases between the ages of 2 and 3 (Nicklaus et al., 2005b). The diversity of intake lowers between the ages of 2 and 5 (Cox et al., 1997), and picky children have a less varied diet (Carruth et al., 1998; Falciglia et al., 2000). Between the ages of 2 and 9, neophobic children eat less fruit, and especially less vegetables (Cooke et al., 2003; Galloway et al., 2003, 2005; 
Jacobi et al., 2003). Follow-ups in birth cohorts show that children with eating difficulties (poor eating, food refusal, unable to get into a routine), as described by their parents at 2 years, were likely to have lower fruit and vegetable intake, as well as a lower variety score at 3-5 years than those with no difficulty. This suggests that the presence of eating difficulties could be an early indicator of a worse dietary profile later in life (de Lauzon-Guillain et al., 2014). Moreover, picky eaters were twice more likely to be underweight at 4.5 years than children who had never been picky (Dubois et al., 2007).

Could food neophobia be prevented by early flavor exposure? First, one has to consider whether food neophobia is associated with sensitivity to flavors. In a study where taste and olfactory sensitivities were reported by the parents, thanks to a questionnaire, a higher "taste/smell sensitivity" was found to be associated with lower fruit and vegetable consumption, lower variety of liked fruit and vegetable, and higher food neophobia in 2- to 5-year-old children (Coulthard and Blissett, 2009). The relationship between food neophobia and intake of plant-based foods may be partly mediated by sensitivity to the bitterness of PROP, at least in boys (Tsuji et al., 2012). Assessing smell and taste differential reactivity in toddlers (ie, reactivity toward several stimuli) using experimental behavioral measurements, as well as food neophobia with a questionnaire, enabled to show that food neophobia scores were modestly but significantly positively correlated with smell differential reactivity, but not with taste differential reactivity (Monnery-Patris et al., 2015). This suggests that foods that do not "smell right" to food neophobic children may be initially rejected based on olfactory cues alone. This confirms that the olfactory system warns children about potentially dangerous foods that may be toxic or are unknown.

Evaluating the effect of "overall" flavor exposure on food preferences and food neophobia is relatively challenging, since characterizing overall exposure in terms of odors or tastes is not easy to systematize, as noted earlier. On the one hand, some studies have shown the stability of food preferences from the early years on until later in childhood (Nicklaus et al., 2004, 2005a; Nicklaus and Remy, 2013; Skinner et al., 2002a,b). On the other hand, some studies have tried to evaluate the impact of feeding experience, after the introduction of complementary foods, on later preferences (Hetherington et al., 2015; Yuan et al., 2016). The first study evaluated the effect of a progressive introduction of flavor variety in the infant diet, first in milk, then in cereals (Hetherington et al., 2015). Infants who received a variety of flavors in milk, then in rice cereal liked and ate the target vegetable purees more than infants with regular care immediately after the intervention; but the effect was not sustained at the 6- and 18-month follow-ups, thus providing evidence of a short-term effect of flavor exposure. In the second study, liking of 5-year-old children for several food categories ("fruit and vegetables," "meat, fish and eggs," desserts and cheese) was evaluated by direct interview of the children (Yuan et al., 2016). Structural modeling showed that food neophobia at 4 years predicted liking for all food groups; but infant feeding experience during the first year was not systematically associated with children's liking: it was only observed for the meat/fish/eggs group. Further research is clearly needed to clarify and systematize the analysis of early flavor exposure on the establishment of sustainable healthy eating habits. 


\subsection{Conclusions}

It appears clearly that children are exposed to a variety of flavors during their uterine and postnatal life, and as their chemosensory senses become functional, these exposures are likely to further modify their flavor and food preferences. Altogether, the familiarity with a flavor appears as critical for the acceptance of foods bearing this flavor and, most likely, the earlier the flavor exposure, the higher the acceptance of this flavor. However, several of the studies showing an effect of early flavor exposure also suggest that this learning phenomenon is relatively specific to each flavor/taste. In some instances, it appears conceivable that the effect of flavor exposure may generalize to new flavor/food, even in the absence of a specific exposure, as in the case of flavor exposure through breastfeeding, but there are still a lot of aspects to understand more deeply in this area. How sustainable are flavor learning effects related to exposure at different early stages? Are there specific periods when flavor exposure is more likely to produce sustainable effects on food preference? May early flavor exposure really reduce food neophobia, and if yes, what would it take? Are taste exposures more impactful on food preferences than flavor exposures? If early flavor exposure works, how can we make sure that they are safe? How to convince parents to modify their feeding practices in order to promote a variety of flavor exposure? The future of research in this area is likely to bring interesting insight to these questions.

\section{References}

Abate, P., Pueta, M., Spear, N.E., Molina, J.C., 2008. Fetal learning about ethanol and later ethanol responsiveness: evidence against safe amounts of prenatal exposure. Exp. Biol. Med. 233, 139-154.

Abraham, E.C., Godwin, J., Sherriff, A., Armstrong, J., 2012. Infant feeding in relation to eating patterns in the second year of life and weight status in the fourth year. Pub. Health Nutr. $15,1705-1714$.

Agostoni, C., Carratu, B., Boniglia, C., Riva, E., Sanzini, E., 2000. Free amino acid content in standard infant formulas: comparison with human milk. J. Am. Coll. Nutr. 19, 434-438.

Ashman, A.M., Collins, C.E., Hure, A.J., Jensen, M., Oldmeadow, C., 2014. Maternal diet during early childhood, but not pregnancy, predicts diet quality and fruit and vegetable acceptance in offspring. Matern. Child Nutr. doi: 10.1111/mcn.12151.

Barends, C., de Vries, J., Mojet, J., de Graaf, C., 2013. Effects of repeated exposure to either vegetables or fruits on infant's vegetable and fruit acceptance at the beginning of weaning. Food Qual. Prefer. 29, 157-165.

Bateson, P., Barker, D., Clutton-Brock, T., Deb, D., D’Udine, B., Foley, R.A., Gluckman, P., Godfrey, K., Kirkwood, T., Lahr, M.M., McNamara, J., Metcalfe, N.B., Monaghan, P., Spencer, H.G., Sultan, S.E., 2004. Developmental plasticity and human health. Nature 430, 419-421.

Beauchamp, G.K., Moran, M., 1982. Dietary experience and sweet taste preferences in human infants. Appetite 3, 139-152.

Beauchamp, G.K., Moran, M., 1984. Acceptance of sweet and salty tastes in 2-year-old children. Appetite 5, 291-305. 
Bingham, P.M., Abassi, S., Sivieri, E., 2003a. A pilot study of milk odor effect on nonnutritive sucking by premature newborns. Arch. Pediatr. Adolesc. Med. 157, 72-75.

Bingham, P.M., Stevens-Tuttle, D., Lavin, E., Acree, T., 2003b. Odorants in breast milk. Arch. Pediatr. Adolesc. Med. 157, 1031.

Bingham, P.M., Churchill, D., Ashikaga, T., 2007. Breast milk odor via olfactometer for tubefed, premature infants. Behav. Res. Methods 39, 630-634.

Birch, L.L., Gunder, L., Grimm-Thomas, K., Laing, D.G., 1998. Infants' consumption of a new food enhance acceptance of similar foods. Appetite 30, 283-295.

Bouhlal, S., Issanchou, S., Nicklaus, S., 2011. The impact of salt, fat and sugar levels on toddler food intake. Br. J. Nutr. 105, 645-653.

Bouhlal, S., Issanchou, S., Chabanet, C., Nicklaus, S., 2014. "Just a pinch of salt." An experimental comparison of the effect of repeated exposure and flavor-flavor learning with salt or spice on vegetable acceptance in toddlers. Appetite 83, 209-217.

Bower, E., Szajer, J., Mattson, S.N., Riley, E.P., Murphy, C., 2013. Impaired odor identification in children with histories of heavy prenatal alcohol exposure. Alcohol 47, 275-278.

Buettner, A., 2007. A selective and sensitive approach to characterize odour-active and volatile constituents in small-scale human milk samples. Flav. Fragr. J. 22, 465-473.

Burnier, D., Dubois, L., Girard, M., 2011. Exclusive breastfeeding duration and later intake of vegetables in preschool children. Eur. J. Clin. Nutr. 65, 196-202.

Butte, N., Cobb, K., Dwyer, J., Graney, L., Heird, W., Rickard, K., 2004. The start healthy feeding guidelines for infants and toddlers. J. Am. Diet. Assoc. 104, 442-454.

Cadiou, H., Aoude, I., Tazir, B., Molinas, A., Fenech, C., Meunier, N., Grosmaitre, X., 2014. Postnatal odorant exposure induces peripheral olfactory plasticity at the cellular level. J. Neurosci. 34, 4857-4870.

Carruth, B.R., Skinner, J.D., Houck, K., Moran, III, J., Coletta, F., Ott, D., 1998. The phenomenon of Picky Eater: a behavioral marker in eating patterns of toddlers. J. Am. Coll. Nutr. 17, 180-186.

Caton, S.J., Blundell, P., Ahern, S.M., Nekitsing, C., Olsen, A., Møller, P., Hausner, H., Remy, E., Nicklaus, S., Chabanet, C., Issanchou, S., Hetherington, M.M., 2014. Learning to eat vegetables in early life: the role of timing, age and individual eating traits. PLoS One 9, e97609.

Cooke, L., Wardle, J., Gibson, E.L., 2003. Relationship between parental report of food neophobia and everyday food consumption in 2-6-year-old children. Appetite 41, 205-206.

Coulthard, H., Blissett, J., 2009. Fruit and vegetable consumption in children and their mothers: moderating effects of child sensory sensitivity. Appetite 52, 410-415.

Coulthard, H., Harris, G., Fogel, A., 2014. Exposure to vegetable variety in infants weaned at different ages. Appetite 78, 89-94.

Cox, D.R., Skinner, J.D., Carruth, B.R., Moran, III, J., Houck, K.S., 1997. A food variety index for toddlers (VIT): development and application. J. Am. Diet. Assoc. 97, 1382-1386.

Crystal, S.R., Berstein, I.L., 1995. Morning sickness: impact of offspring salt preference. Appetite 25, 231-240.

Crystal, S.R., Berstein, I.L., 1998. Infant salt preference and mother's morning sickness. Appetite 30, 297-307.

de Lauzon-Guillain, B., Jones, L., Oliveira, A., Moschonis, G., Betoko, A., Lopes, C., Moreira, P., Manios, Y., Papadopoulos, N.G., Emmett, P., Charles, M.A., 2013. The influence of early feeding practices on fruit and vegetable intake among preschool children in 4 European birth cohorts. Am. J. Clin. Nutr. 98, 804-812.

de Lauzon-Guillain, B., Jones, L., Oliveira, A., Moschonis, G., Betoko, A., Lopes, C., Moreira, P., Manios, Y., Papadopoulos, N.G., Emmett, P., Charles, M., 2014 Early feeding practices 
and later food habits. In: Final Habeat symposium on Improving Infant and Child Eating Habits, Encouraging Fruit and Vegetable Intake, Dijon, France, 1 p.

de Wild, V., de Graaf, C., Jager, G., 2014. Efficacy of repeated exposure and flavour-flavour learning as mechanisms to increase preschooler's vegetable intake and acceptance. Pediatr. Obes. 10 (3), 205-212.

Delaunay-El Allam, M., Marlier, L., Schaal, B., 2006. Learning at the breast: preference formation for an artificial scent and its attraction against the odor of maternal milk. Infant Behav. Dev. 29, 308-321.

Delaunay-El Allam, M., Soussignan, R., Patris, B., Marlier, L., Schaal, B., 2010. Long-lasting memory for an odor acquired at the mother's breast. Dev. Sci. 13, 849-863.

Denzer, M.Y., Kirsch, F., Buettner, A., 2015. Are odorant constituents of herbal tea transferred into human milk? J. Agric. Food Chem. 63, 104-111.

Doucet, S., Soussignan, R., Sagot, P., Schaal, B., 2009. The secretion of areolar (Montgomery's) glands from lactating women elicits selective, unconditional responses in neonates. PLoS One 4, e7579.

Doucet, S., Soussignan, R., Sagot, P., Schaal, B., 2012. An overlooked aspect of the human breast: areolar glands in relation with breastfeeding pattern, neonatal weight gain, the dynamics of lactation. Early Hum. Dev. 88, 119-128.

Dovey, T.M., Staples, P.A., Gibson, E.L., Halford, J.C.G., 2008. Food neophobia and "picky/ fussy" eating in children: a review. Appetite 50, 181-193.

Dubois, L., Farmer, A., Girard, M., Peterson, K., Tatone-Tokuda, F., 2007. Problem eating behaviors related to social factors and body weight in preschool children: a longitudinal study. Int. J. Behav. Nutr. Phys. Act. 4, 9.

Emmett, P.M., Rogers, I.S., 1997. Properties of human milk and their relationship with maternal nutrition. Early Hum. Dev. 49, S7-S28.

Falciglia, G.A., Couch, S.C., Gribble, L.S., Pabsta, S.M., Frank, R., 2000. Food neophobia in childhood affects dietary variety. J. Am. Diet. Assoc. 100, 1474-1481.

Fildes, A., Lopes, C., Moreira, P., Moschonis, G., Oliveira, A., Mavrogianni, C., Manios, Y., Beeken, R., Wardle, J., Cooke, L., 2015. An exploratory trial of parental advice for increasing vegetable acceptance in infancy. Br. J. Nutr. 114, 328-336.

Forestell, C.A., Mennella, J.A., 2007. Early determinants of fruit and vegetable acceptance. Pediatrics 120, 1247-1254.

Galloway, A.T., Lee, Y., Birch, L.L., 2003. Predictors and consequences of food neophobia and pickiness in young girls. J. Am. Diet. Assoc. 103, 692-698.

Galloway, A.T., Fiorito, L., Lee, Y., Birch, L.L., 2005. Parental pressure, dietary patterns, and weight status among girls who are picky eaters. J. Am. Diet. Assoc. 105, 541-548.

Ganchrow, J.R., Mennella, J.A., 2003. The ontogeny of human flavor perception. In: Doty, R.L. (Ed.), Handbook of Olfaction and Gustation. Michael Dekker, New York, pp. 823-846.

Geraghty, S.R., McNamara, K., Kwiek, J.J., Rogers, L., Klebanoff, M.A., Augustine, M., Keim, S.A., 2015. Tobacco metabolites and caffeine in human milk purchased via the Internet. Breastfeed. Med. 10, 419-424.

Gerrish, C.J., Mennella, J.A., 2001. Flavor variety enhances food acceptance in formula-fed infants. Am. J. Clin. Nutr. 73, 1080-1085.

Gillman, M.W., Ludwig, D.S., 2013. How early should obesity prevention start? N. Engl. J. Med. 369, 2173-2175.

Grieger, J.A., Scott, J., Cobiac, L., 2011. Dietary patterns and breast-feeding in Australian children. Pub. Health Nutr. 14, 1939-1947.

Haller, R., Rummel, C., Henneberg, S., Pollmer, U., Köster, E.P., 1999. The influence of early experience with vanillin on food preference later in life. Chem. Senses 24, 465-467. 
Harris, G., Thomas, A., Booth, D.A., 1990. Development of salt taste in infancy. Dev. Psychol. 26, 534-538.

Hausner, H., 2009. Early Predictors of Human Food Preferences. Unpublished PhD thesis, University of Copenhagen, Copenhagen.

Hausner, H., Bredie, W.L.P., Mølgaard, C., Petersen, M.A., Møller, P., 2008. Differential transfer of dietary flavour compounds into human breast milk. Physiol. Behav. 95, 118-124.

Hausner, H., Philipsen, M., Skov, T.H., Petersen, M.A., Bredie, W.L.P., 2009. Characterization of the volatile composition and variations between infant formulas and mother's milk. Chemosens. Percept. 2, 79-93.

Hausner, H., Nicklaus, S., Issanchou, S., Mølgaard, C., Møller, P., 2010. Breastfeeding facilitates acceptance of a novel dietary flavour compound. Clin. Nutr. 29, 141-148.

Hepper, P.G., 1995. Human fetal olfactory learning. Int. J. Prenatal. Perinatal. Pschycol. Med. 7, 147-151.

Hepper, P.G., Wells, D.L., Dornan, J.C., Lynch, C., 2013. Long-term flavor recognition in humans with prenatal garlic experience. Dev. Psychobiol. 55, 568-574.

Hetherington, M.M., Schwartz, C., Madrelle, J., Croden, F., Nekitsing, C., Vereijken, C.M.J.L., Weenen, H., 2015. A step-by-step introduction to vegetables at the beginning of complementary feeding: the effects of early and repeated exposure. Appetite 84, 280-290.

Issanchou, S., Nicklaus, S., 2015. Sensitive periods and factors in the early formation of food preferences. In: Frelut, M.-L. (Ed.), The ECOG's eBook on Child and Adolescent Obesity.

Jacobi, C., Agras, W.S., Bryson, S., Hammer, L.D., 2003. Behavioral validation, precursors, and concomitants of picky eating in childhood. J. Am. Acad. Child Adolesc. Psychiatr. 42, 76-84.

Jagnow, C.P., Simon, C.M., Beauchamp, G.K., Mennella, J.A., 2000. Pre- and postnatal exposure to the flavor of carrots affects the infants' acceptance of carrot-flavored cereal. Chem. Senses 25 (616), 667.

Jensen, R.G., 1995. Handbook of Milk Composition. Academic Press, New York, NY.

Lange, C., Visalli, M., Jacob, S., Chabanet, C., Schlich, P., Nicklaus, S., 2013. Maternal feeding practices during the first year and their impact on infants' acceptance of complementary food. Food Qual. Prefer. 29, 89-98.

Leshem, M., 1998. Salt preference in adolescence is predicted by common prenatal and infantile mineralofluid loss. Physiol. Behav. 63, 699-704.

Liem, D.G., Mennella, J.A., 2002. Sweet and sour preferences during childhood: role of early experiences. Dev. Psychobiol. 41, 388-395.

Maier, A., Chabanet, C., Schaal, B., Issanchou, S., Leathwood, P., 2007. Effects of repeated exposure on acceptance of initially disliked vegetables in 7-month old infants. Food Qual. Prefer. 18, 1023-1032.

Maier, A.S., Chabanet, C., Schaal, B., Leathwood, P.D., Issanchou, S.N., 2008. Breastfeeding and experience with variety early in weaning increase infants' acceptance of new foods for up to two months. Clin. Nutr. 27, 849-857.

Málaga, I., Arguelles, J., Díaz, J.J., Perillán, C., Vijande, M., Málaga, S., 2005. Maternal pregnancy vomiting and offspring salt taste sensitivity and blood pressure. Pediatr. Nephrol. 20, 956-960.

Mantella, N.M., Kent, P.F., Youngentob, S.L., 2013. Fetal nicotine exposure increases preference for nicotine odor in early postnatal and adolescent, but not adult, rats. PLoS One 8, e84989.

Marlier, L., 2009. Émergence et développement précoce des préférences olfactives et alimentaires. Archives de Pediatrie 16, 532-534. 
Marlier, L., Schaal, B., 2005. Human newborns prefer human milk: conspecific milk odor is attractive without postnatal exposure. Child Dev. 76, 155-168.

Marlier, L., Schaal, B., Soussignan, R., 1997. Orientation responses to biological odours in the human newborn. Initial pattern and postnatal plasticity. CR Acad. Sci. Paris Sci. 320, 999-1005.

Marlier, L., Schaal, B., Soussignan, R., 1998. Bottle-fed neonates prefer an odor experienced in utero to an odor experienced postnatally in the feeding context. Dev. Psychobiol. 33, 133-145.

Marlier, L., Schaal, B., Gaugler, C., Messer, J., 2001. Olfaction in premature human newborns: detection and discrimination abilities two months before gestational term. In: Marchlewska-Koj, A., Lepri, J.J., Müller-Schwarze, D. (Eds.), Chemical signals in vertebrates 9. Kluwer Academic, New York, NY, pp. 205-209.

Marlier, L., Gaugler, C., Messer, J., 2005. Olfactory stimulation prevents apnea in premature newborns. Pediatrics 115, 83-88.

Martin, C., Visalli, M., Lange, C., Schlich, P., Issanchou, S., 2014. Creation of a food taste database using an in-home taste profile method. Food Qual. Prefer. 36, 70-80.

Mennella, J.A., 1995. Mother's milk: a medium for early flavor experiences. J. Hum. Lact. 11, $39-45$.

Mennella, J.A., 2001. Regulation of milk intake after exposure to alcohol mothers' milk. Alcoholism 25, 590-593.

Mennella, J.A., Beauchamp, G.K., 1991a. Maternal diet alters the sensory qualities of human milk and the nursling's behavior. Pediatrics 88, 737-744.

Mennella, J.A., Beauchamp, G.K., 1991b. The transfer of alcohol to human milk. Effects on flavor and the infant's behavior. N. Engl. J. Med. 325, 981-985.

Mennella, J.A., Beauchamp, G.K., 1993. The effects of repeated exposure to garlic-flavored milk on the nursling's behavior. Pediatr. Res. 34, 805-808.

Mennella, J.A., Beauchamp, G.K., 1996a. Developmental changes in the acceptance of protein hydrolysate formula. J. Dev. Behav. Pediatr. 17, 386-391.

Mennella, J.A., Beauchamp, G.K., 1996b. The human infants' responses to vanilla flavors in human milk and formula. Infant Behav. Dev. 19, 13-19.

Mennella, J.A., Beauchamp, G.K., 1999. Experience with a flavor in mother's milk modifies the infant's acceptance of flavored cereal. Dev. Psychobiol. 35, 197-203.

Mennella, J.A., Beauchamp, G.K., 2002. Flavor experiences during formula feeding are related to preferences during childhood. Early Hum. Dev. 68, 71-82.

Mennella, J.A., Jagnow, C.P., Beauchamp, G.K., 2001. Prenatal and postnatal flavor learning by human infants. Pediatrics 107, e88.

Mennella, J.A., Griffin, C.E., Beauchamp, G.K., 2004. Flavor programming during infancy. Pediatrics 113, 840-845.

Mennella, J.A., Kennedy, J.M., Beauchamp, G.K., 2006. Vegetable acceptance by infants: effects of formula flavors. Early Hum. Dev. 82, 463-468.

Mennella, J.A., Nicklaus, S., Jagolino, A.L., Yourshaw, L.M., 2008. Variety is the spice of life: strategies for promoting fruit and vegetable acceptance during infancy. Physiol. Behav. 94, 29-38.

Mennella, J.A., Forestell, C.A., Morgan, L.K., Beauchamp, G.K., 2009. Early milk feeding influences taste acceptance and liking during infancy. Am. J. Clin. Nutr. 90, 780S-788S.

Mennella, J.A., Lukasewycz, L.D., Castor, S.M., Beauchamp, G.K., 2011. The timing and duration of a sensitive period in human flavor learning: a randomized trial. Am. J. Clin. Nutr. 93, 1019-1024. 
Monnery-Patris, S., Wagner, S., Rigal, N., Schwartz, C., Chabanet, C., Issanchou, S., Nicklaus, S., 2015. Smell differential reactivity, but not taste differential reactivity, is related to food neophobia in toddlers. Appetite 95, 303-309.

Nicklaus, S., 2009. Development of food variety in children. Appetite 52, 253-255.

Nicklaus, S., 2011. Children's acceptance of new foods at weaning. Role of practices of weaning and of food sensory properties. Appetite 57, 812-815.

Nicklaus, S., 2015. The role of food experiences during early childhood in food pleasure learning. Appetite. doi: 10.1016/j.appet.2015.08.022.

Nicklaus, S., Remy, E., 2013. Early origins of overeating: tracking between early food habits and later eating patterns. Curr. Obes. Rep. 2, 179-184.

Nicklaus, S., Boggio, V., Chabanet, C., Issanchou, S., 2004. A prospective study of food preferences in childhood. Food Qual. Prefer. 15, 805-818.

Nicklaus, S., Boggio, V., Chabanet, C., Issanchou, S., 2005a. A prospective study of food variety seeking in childhood, adolescence and early adult life. Appetite 44, 289-297.

Nicklaus, S., Chabanet, C., Boggio, V., Issanchou, S., 2005b. Food choices at lunch during the third year of life: increase in energy intake but decrease in variety. Acta Paediatr. 94, 1023-1029.

Nicklaus, S., Chabanet, C., Lange, C., Schlich, P., Monnery-Patris, S., Issanchou, S., 2014. Unravelling some early determinants of liking for vegetables at 2 years: a longitudinal study from pregnancy to 2 years. In: Society for the Study of Ingestive Behavior (SSIB) 2014, Seattle, WA.

Nicklaus, S., Demonteil, L., Tournier, C., 2015. Modifying the texture of foods for infants and young children. In: Chen, J., Rosenthal, A. (Eds.), Modifying Food Texture. Elsevier Ltd, Cambrige, UK, pp. 187-222.

Oostindjer, M., Bolhuis, J.E., van den Brand, H., Kemp, B., 2009. Prenatal flavor exposure affects flavor recognition and stress-related behavior of piglets. Chem. Senses 34, 775-787.

Oostindjer, M., Bolhuis, J.E., van den Brand, H., Roura, E., Kemp, B., 2010. Prenatal flavor exposure affects growth, health and behavior of newly weaned piglets. Physiol. Behav. 99, 579-586.

Oostindjer, M., Bolhuis, J.E., Simon, K., van den Brand, H., Kemp, B., 2011. Perinatal flavour learning and adaptation to being weaned: all the pig needs is smell. PLoS One 6, e25318.

Porter, R.H., Winberg, J., 1999. Unique salience of maternal breast odors for newborn infants. Neurosci. Biobehav. Rev. 23, 439-449.

Prescott, S.L., 2010. Allergic disease: understanding how in utero events set the scene. Proc. Nutr. Soc. 69, 366-372.

Remy, E., Issanchou, S., Chabanet, C., Nicklaus, S., 2013. Repeated exposure of infants at complementary feeding to a vegetable puree increases acceptance as effectively as flavor-flavor learning and more effectively than flavor-nutrient learning. J. Nutr. 143, 1194-1200.

Schaal, B., 1988. Olfaction in infants and children: developmental and functional perspectives. Chem. Senses 13, 145-190.

Schaal, B., Orgeur, P., 1992. Olfaction in utero—can the rodent model be generalised? Quart. J. Exp. Psychol. B 44B, 245-278.

Schaal, B., Marlier, L., Soussignan, R., 2000. Human foetuses learn odours from their pregnant mother's diet. Chem. Senses 25, 729-737.

Schaal, B., Doucet, S., Sagot, P., Hertling, E., Soussignan, R., 2006. Human breast areolae as scent organs: morphological data and possible involvement in maternal-neonatal coadaptation. Dev. Psychobiol. 48, 100-110. 
Schaal, B., Doucet, S., Soussignan, R., Rietdorf, M., Weibchen, G., Francke, W., 2008. The human breast as a scent organ: exocrine structures, secretions, volatile components, and possible functions in breastfeeding interactions. Hurts, J.L., Benyon, R.J., Roberts, S.C., Wyatt, T.D. (Eds.), Chemical Signals in Vertebrates, vol. 11, Springer, New York, NY, pp. 325-335.

Schwartz, C., Issanchou, S., Nicklaus, S., 2009. Developmental changes in the acceptance of the five basic tastes in the first year of life. Br. J. Nutr. 102, 1375-1385.

Schwartz, C., Chabanet, C., Boggio, V., Lange, C., Issanchou, S., Nicklaus, S., 2010. À quelles saveurs les nourrissons sont-ils exposés dans la première année de vie ? To which tastes are infants exposed during the first year of life? Archives de Pediatrie 17, 1026-1034.

Schwartz, C., Chabanet, C., Lange, C., Issanchou, S., Nicklaus, S., 2011a. The role of taste in food acceptance at the beginning of complementary feeding. Physiol. Behav. 104, 646-652.

Schwartz, C., Scholtens, P., Lalanne, A., Weenen, H., Nicklaus, S., 2011b. Development of healthy eating habits early in life: review of recent evidence and selected guidelines. Appetite 57, 796-807.

Schwartz, C., Chabanet, C., Laval, C., Issanchou, S., Nicklaus, S., 2013. Breastfeeding duration: influence on taste acceptance over the first year of life. Br. J. Nutr. 109, 1154-1161.

Scott, J.A., Chih, T.Y., Oddy, W.H., 2012. Food variety at 2 years of age is related to duration of breastfeeding. Nutrients 4, 1464-1474.

Shimoda, M., Yoshimura, T., Ishikawa, H., Hayakawa, I., Osajima, Y., 2000. Volatile compounds of human milk. J. Fac. Agric. Kyushu Univ. 45, 199-206.

Shirazki, A., Weintraub, Z., Reich, D., Gershon, E., Leshem, M., 2007. Lowest neonatal serum sodium predicts sodium intake in low birth weight children. Am. J. Physiol. Regul. Integr. Comp. Physiol. 292, R1683-R1689.

Singhal, A., Cole, T.J., Lucas, A., 2001. Early nutrition in preterm infants and later blood pressure: two cohorts after randomised trials. Lancet 357, 413-419.

Skinner, J.D., Carruth, B.R., Bounds, W., Ziegler, P.J., 2002a. Children's food preferences: a longitudinal analysis. J. Am. Diet. Assoc. 102, 1638-1647.

Skinner, J.D., Carruth, B.R., Bounds, W., Ziegler, P., Reidy, K., 2002b. Do food-related experiences in the first 2 years of life predict dietary variety in school-aged children? J. Nutr. Educ. Behav. 34, 310-315.

Stein, L.J., Cowart, B.J., Beauchamp, G.K., 2012. The development of salty taste acceptance is related to dietary experience in human infants: a prospective study. Am. J. Clin. Nutr. 95, $123-129$.

Sullivan, S.A., Birch, L.L., 1994. Infant dietary experience and acceptance of solid foods. Pediatrics 93, 271-277.

Taveras, E.M., Scanlon, K.S., Birch, L., Rifas-Shiman, S.L., Rich-Edwards, J.W., Gillman, M.W., 2004. Association of breastfeeding with maternal control of infant feeding at age 1 year. Pediatrics 114, e577-e583.

Taveras, E.M., Rifas-Shiman, S.L., Scanlon, K.S., Grummer-Strawn, L.M., Sherry, B., Gillman, M.W., 2006. To what extent is the protective effect of breastfeeding on future overweight explained by decreased maternal feeding restriction? Pediatrics 118, 2341-2348.

The Commission of the European Communities, 2006. Commission directive 2006/125/EC of 5 December 2006 on processed cereal-based foods and baby foods for infants and young children. Available from: http://eur-lex.europa.eu/LexUriServ/LexUriServ.do?uri=OJ:L:2 006:339:0016:0035:EN:PDF

Tisi, D.K., Burns, D.H., Luskey, G.W., Koski, K.G., 2011. Fetal exposure to altered amniotic fluid glucose, insulin, and insulin-like growth factor-binding protein 1 occurs before screening for gestational diabetes mellitus. Diabetes Care 34, 139-144. 
Todrank, J., Heth, G., Restrepo, D., 2011. Effects of in utero odorant exposure on neuroanatomical development of the olfactory bulb and odour preferences. Proc. Biol. Sci. 278, 1949-1955.

Tsuji, M., Nakamura, K., Tamai, Y., Wada, K., Sahashi, Y., Watanabe, K., Ohtsuchi, S., Ando, K., Nagata, C., 2012. Relationship of intake of plant-based foods with 6-n-propylthiouracil sensitivity and food neophobia in Japanese preschool children. Eur. J. Clin. Nutr. 66, 47-52.

Viskaal-van Dongen, M., van den Berg, M.C., Vink, N., Kok, F.J., de Graaf, C., 2012. Taste-nutrient relationships in commonly consumed foods. Br. J. Nutr. 108, 140-147.

Wagner, S., Issanchou, S., Chabanet, C., Lange, C., Schaal, B., Monnery-Patris, S., 2014. Liking the odour, liking the food. Toddlers' liking of strongly flavoured foods correlates with liking of their odour. Appetite 81, 60-66.

WHO, 2003. Feeding and nutrition of infants and young children. Guidelines for the WHO European Region, with Emphasis on the Former Soviet Countries. Unpublished N 87, pp $1-288$.

Yuan, W., Rigal, N., Monnery-Patris, S., Chabanet, C., Charles, M.A., de Lauzon-Guillain, B., EDEN mother-child Study Group, 2016. Early food exposures and food liking in 5-y old children: a longitudinal study from the EDEN mother-child cohort. Int. J. Behav. Nutr. Phys. Act. 13, 1-10.

Zhang, G.-H., Chen, M.-L., Liu, S.-S., Zhan, Y.-H., Quan, Y., Qin, Y.-M., Deng, S.-P., 2011. Effects of mother's dietary exposure to Acesulfame-K in pregnancy or lactation on the adult offspring's sweet preference. Chem. Senses 36, 763-770. 